\title{
Optimization of Turning Process and Cutting Force Using Multiobjective Genetic Algorithm
}

\author{
Afrim Gjelaj ${ }^{1}$, Besart Berisha ${ }^{2, *}$, Fidan Smaili $^{2}$ \\ ${ }^{1}$ Faculty of Mechanical Engineering, University of Prishtina, Kosovo \\ ${ }^{2}$ Faculty of Mechanical Engineering, University of Maribor, Slovenia
}

Copyright $(2019$ by authors, all rights reserved. Authors agree that this article remains permanently open access under the terms of the Creative Commons Attribution License 4.0 International License

\begin{abstract}
Application of artificial intelligence in manufacturing process has great impact factor. This work paper is focused into optimization of machining by turning process regarding to the analysing of tool selection (TS), tool path length (TPL) and machining parameters for turning operation using the artificial Intelligence. Except of solving of problems for tool selection and tool path length, here also will be analysed the cutting force $(\mathrm{Fc})$ by turning process whereas as case of research material is steel $\mathrm{C} 45$. The results of measurement of the main cutting force Fc, are compared and predicted in theoretical and practical way. Also, all of requirements are fulfilled in regard of the expression. In same time are optimized the main machining parameters regarding to the cutting force with utilization of the Multi-Objective Genetic Algorithm (MOGA). Results for cutting power Pc and Metal removal rate MRR using Pareto Front are obtained using MOGA.
\end{abstract}

Keywords Optimization, Machining Parameters, Tool Path, Cutting Force, Artificial Intelligence

\section{Introduction}

In our work is discussed the tool path length, tool selection, and plan preparation technology for a turning operation. Special attention is dedicated to the tool path length, cutting force, main machining parameter for rotating workpieces, which is prepared for optimization within a MATLAB environment. The optimizations in this case include the path trajectories for each segment of length based on the geometry of the workpiece.

The rotational workpiece designs could be considered as $2 \mathrm{D}$ models. In view of the complexity of the workpiece, complex geometrical models can also be performed (3D machining operation). Therefore, in order to optimize the tool path length by turning, as well as finding the best solution for tool selection based on the geometry of the workpiece for one optimal tool path length. At the same time the machining parameters such as depth of cutting, feed rate, and cutting speed are optimized by employing a Genetic Algorithm for our case.

In this section the goal is to optimize the path length for the rotational workpiece, namely external turning. External turning is oriented towards both primary and secondary operations of machining; Primary machining operation of turning; chamfer, facing, radius, concave, convex, tapering, cylindrical etc. Secondary operation machining of turning; groove, recess, knurling, threading, cutting etc.

The machining operation by turning could utilize other methods for optimizing the tool path length. However, we suggested using the Genetic Algorithm as the more popular method for optimizing of the path at the same time as reducing the original diameter $\mathrm{D}$ of the workpiece to the desired diameter D1 as shown in (Fig. 1).

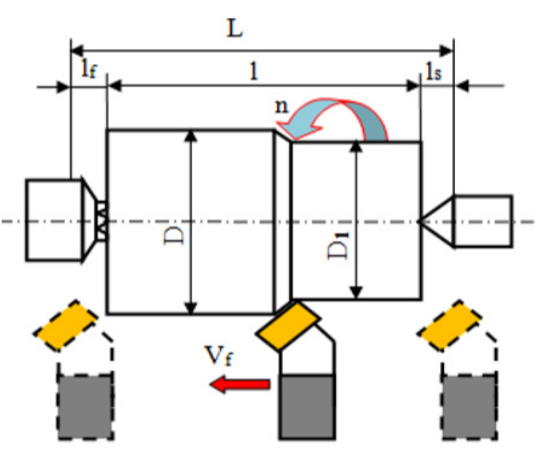

Figure 1. Left is presented the stock material as above, and the longitudinal turning operation in the right [11] 
For personal preference, you may import styles into your own manuscript. The process is divided into 4 steps:

Applying of Multi objective genetic algorithm (MOGA) by focusing on the developing specifically for problems with multiple objectives [5].

By applying artificial intelligence during the turning operation such as the genetic algorithm, discrete system, neural network or fuzzy logic, it is possible to minimize some errors whilst at the same time reducing the cost of machining in industry.

Presented an automatic cutting tool selection method for rough turning operations on $\mathrm{CNC}$ lathe machines [6, 1]. Their method during the cutting tools' selection procedure is made from an appropriate tool library and a heuristic method is employed in order to reduce the time. This procedure eliminates the need for an exhaustive search of the library and results in a very fast and efficient algorithm.

Describing and optimizing of tool path length for linear, circular and spline interpolation with using of the Genetic Algorithm [5]. The application of genetic algorithm has contributed directly in optimize tool path generation in automatic and intelligent $\mathrm{CNC}$ programming machine tools.

The describing of the tool sequence selection as an important activity in process-planning for milling and it has great bearing on the cost of machining. A Genetic Algorithm (GA) formulation is used to find the optimal tool sequence.

Two types of selection mechanisms namely "Elitist selection" and "Roulette method" are tested. It is found that the GA formulation generates near optimal solutions whilst reducing computation by up to $30 \%$ as compared to the graph formulation [6].

In (Fig. 2) as follow are presented some cases of tool selection based on the geometry of workpiece.
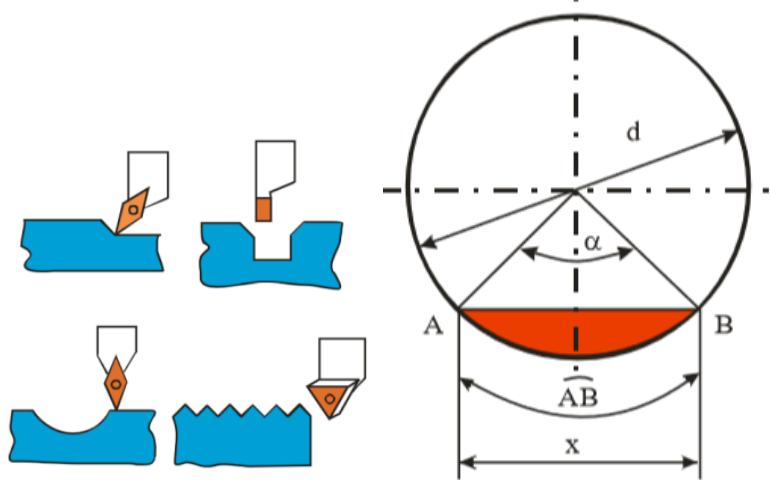

Figure 2. Some cases of path and tool geometry

The case with circular trajectories, as in right side (Fig. 2 ), can be calculated using the expression:

$$
A B=\left[(\pi \cdot d \cdot \alpha) / 360^{\circ}\right]
$$

The goal function was to optimize the tool path length for the turning operation which is given by the expression as follows:

$P_{L 0} \cdot n_{p} \cdot\left(\frac{D_{0}}{L_{0}}\right)+\ldots+\sum_{i=1}^{n} P_{L i}\left(n_{p i} \cdot \frac{D_{i}}{L_{i}}\right) \cdot t_{m}+N_{T}+T_{c h}$

Restrictions on optimizing the cutting force $(\mathrm{Fc})$ and cutting power are given by equation (3).

$$
\begin{aligned}
& v_{\text {min }} \leq v \leq v_{\text {max }} \\
& f_{\text {min }} \leq f \leq f_{\text {max }} \\
& a_{\text {min }} \leq a \leq a_{\text {max }}
\end{aligned}
$$

The describing of the modelling of a turning process using a gravitational search algorithm (GSA). GSA is an optimization algorithm based on Newton's law of universal gravitation and mass interactions [7].

Artificial Neural Network (ANN) model was proposed to predict the cutting temperatures significantly and has affecting by tool life and wear. Firstly, experimental measurements of the cutting forces were performed by means of a dynamometer and then numerical cutting forces and cutting temperatures were analyzed through the finite element model in same time [14].

The multiple regression method and an ANN were used for the prediction of the cutting forces that occur during the orthogonal turning of AISI 316L austenitic stainless steel. Several cutting experiments were conducted during the experimental stage of the study by taking different cutting parameters and coating types into consideration [15].

During our research the GA was used for optimizing the numerical coefficients of predefined polynomial models for describing the observed output variables. The accuracies of the obtained prediction models were proved by means of a testing data set that was excluded from the training data.

\section{Analytical Model for Main Cutting Force Fc}

The most of machine tool and cutting tool selections are utilizations within the field of metal cutting processes. Machine tools (Turning, Milling, etc.,) can generally be divided into aspects of automation that generate high levels of intelligence that in our times are applicable.

The focus of our research was oriented mostly towards the field of Lathe (Turning) machining and the geometry of the cutting tool, which have influences on the cutting forces Fc. The level of automation generated towards the $\mathrm{CNC}$ machine tools enabled the achieving quality, 
accuracy etc. Increasing the level of automation directly caused an increase in the quality of the surface roughness. Cutting force $(\mathrm{Fc})$ had a significant influence on the machining process, and this had directly affected the surface roughness. The cutting force is usually assumed to be proportional to the non-deformed area of the cut. Optimization of cutting parameters plays an important role although there are many factors that affect the machining process.

Explaining of the many of engineering methods of statistics to solve the experimental problem as well as analysed: Regression Model (RM), coefficient of regression $\beta 1$ until $\beta 3$, definition of sums of squares, regression of sum of squares (SSR), total sum of squares (SST), error of sum of squares (SSE), sum of squares in function of coefficient of regression etc. [2].

The cutting force $(\mathrm{Fc})$ depends on the depth of cutting (a). The greater the cutting depth (a) the greater the cutting force $(\mathrm{Fc})$. When determining the cutting, the parameters such as material removal rate MRR, feed rate (f) and depth of cutting (a) are the main parameters but our problem needed more parameters. As for the case of the tool, geometry is one of the more important factors that influence a manufacturing process. Fig. 3 presents the general form of the cutting force in the case of a longitudinal turning operation, as follows.

Experimental setup includes workpiece material C45, type of tool ISO6, also main cutting parameters; cutting speed, feed rate and depth of cut.

The level code for main machining parameters (cutting speed, feed rate and depth of cut) are showed in table 1.

In table 1 are presented the main cutting parameters and level code.

Table 1. The level code of machining parameters

\begin{tabular}{|l|c|c|c|c|}
\hline \multicolumn{2}{|c|}{ Main data and level code } & $\begin{array}{c}\text { Cutting speed } \mathrm{V}[\mathrm{m} / \mathrm{min}] \\
\text { Level code }\left[\mathrm{X}_{1}\right]\end{array}$ & $\begin{array}{c}\text { Feed rate } \mathrm{f}[\mathrm{mm} / \mathrm{rr}] \\
\text { Level code }\left[\mathrm{X}_{2}\right]\end{array}$ & $\begin{array}{c}\text { Depth of cut a[mm] } \\
\text { Level code }\left[\mathrm{X}_{3}\right]\end{array}$ \\
\hline Max value & 1 & 134.28 & 0.13 & 1 \\
\hline Mid value & 0 & 107.388 & 0.05 & 0.75 \\
\hline Min value & -1 & 80.541 & 0.085 & 0.5 \\
\hline
\end{tabular}

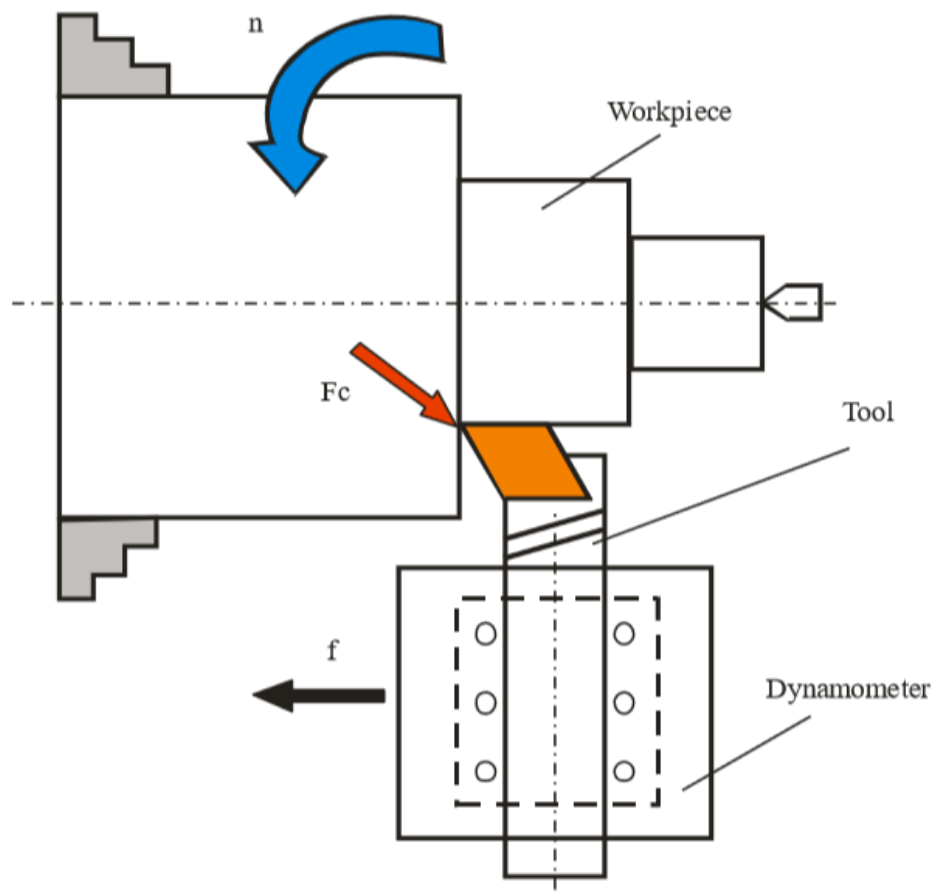

Figure 3. Experiment Setup for measurement of cutting forces by turning process 
The main cutting force $\mathrm{Fc}$ related to the specific cutting force $k c$ could be expressed as:

$$
F_{c}=k_{c} \cdot X_{1}^{\beta_{1}} \cdot X_{2}^{\beta_{2}} \cdot X_{3}^{\beta_{3}}
$$

Where $\beta_{1}, \beta_{2}$ and $\beta_{3}$, denote the exponent regarding to the main cutting force $\mathrm{Fc}$.

The measurements of cutting force $(\mathrm{Fc})$ for steel $\mathrm{C} 45$ are investigated for 12th experiments with combination of main machining parameters. For latest 4th experiment the machining parameters are take same.

Definition of sums of squares is explained in detail based on the equation of regression.

$$
Y=\beta_{0}+\beta_{1} \cdot \text { speed }+\beta_{2} \cdot \text { feed }+\beta_{3} \cdot \text { depthcut }+\varepsilon
$$

where $\mathcal{E}$, is called the error for the ith measurement.

In expression above the $\mathrm{Y}=\mathrm{F}$ is called the dependent variable in our case represent the cutting force, $\mathrm{X} 1, \mathrm{X} 2$ and $\mathrm{X} 3$ is called the independent variable in our case (cutting speed, feed rate and depth of cut), $\beta_{0}, \beta_{1}, \beta_{2}$ and $\beta_{3}$, are the regression coefficients.

When an experiment wants to study several factors simultaneously, the number of different treatments can become quite large in field of milling process (cutting speed, feed rate, depth of cut, radius of tool, clearance angle, rake angle etc.).

The one of main measurement of cutting force in practical way is obtained with results: $\mathrm{Fc}=242.45[\mathrm{~N}]$, and prediction cutting force $\mathrm{Fc}(\mathrm{GA})$ is achieved with results $251.59[\mathrm{~N}]$. The prediction error is obtained $3,77 \%$ based on the experimental and theoretical cutting force by turning operation using the Matlab software.

Also, experimental results of cutting forces $\mathrm{Fc}$ and prediction of cutting forces using artificial intelligence are presented in table 2 .

Table 2. Results for measurement of main cutting force $\mathrm{Fc}$ and prediction error using GA.

\begin{tabular}{|c|c|c|c|}
\hline No. & $\begin{array}{c}\text { Experimental } \\
\text { Fc }\end{array}$ & $\begin{array}{c}\text { Prediction Fc } \\
\text { (GA) }\end{array}$ & $\begin{array}{c}\text { Prediction error } \\
{[\%]}\end{array}$ \\
\hline 1 & 242.45 & 251.59 & 3.77 \\
\hline 2 & 305.7 & 318.32 & 4.128 \\
\hline 3 & 405.5 & 387.11 & 4.535 \\
\hline 4 & 292.11 & 281.38 & 3.673 \\
\hline 5 & 303.99 & 281.38 & 7.438 \\
\hline
\end{tabular}

In figure 4 is showed the measurement of cutting force Fc for experiment number 1, in function of cutting speed (v) and depth of cut (a) where feed rate (f) is get as constant value as follow. Here are presented $5^{\text {th }}$ experiment but are make 12 experiments.

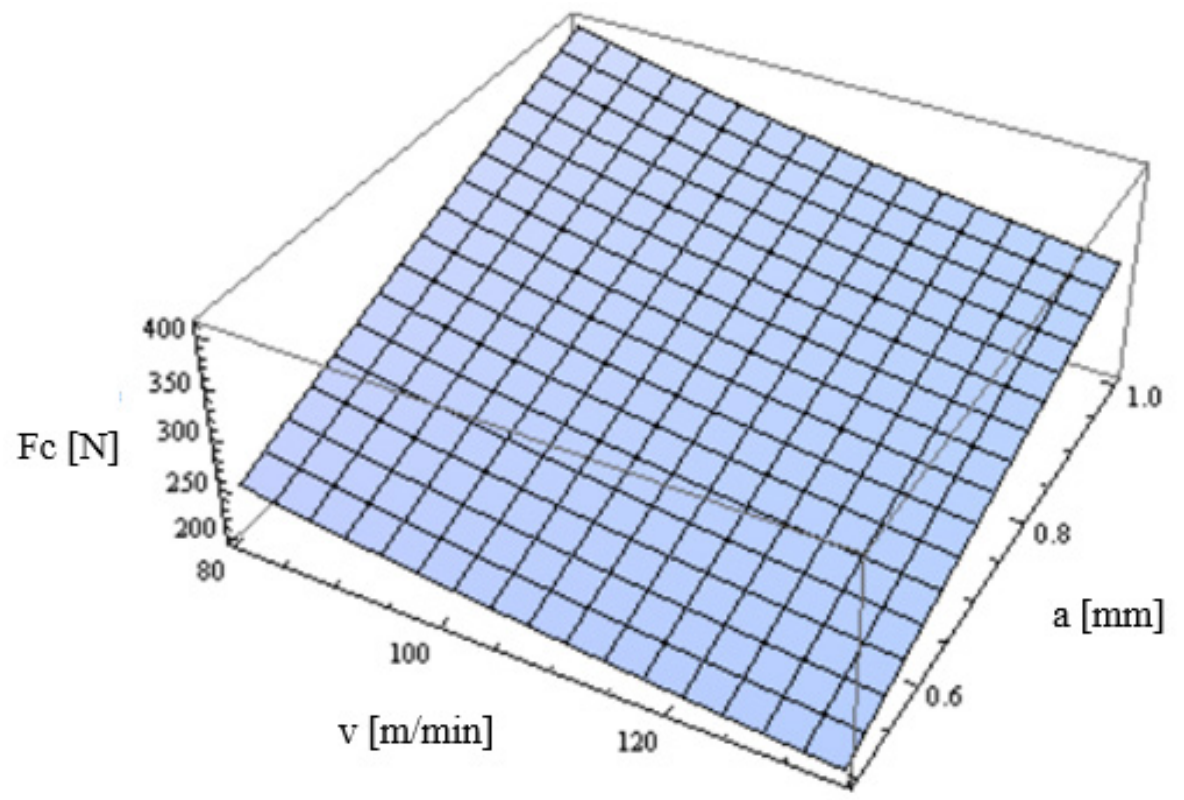

Figure 4. Showed the diagram of main cutting force $\mathrm{Fz}=\mathrm{Fc}$ by turning operation 


\subsection{Multi-objective Optimization for Turning Operation}

Being a population based approaches, Genetic Algorithms (GAs) are well suited for solving multi objective optimization problems. In order to find the optimal solution for a treated problem, the multi objective optimization problems using Genetic Algorithms are employed. This is a very popular problem in practice and can be written in the following form:

$$
\operatorname{minf}(\mathrm{x})=\left\{\begin{array}{l}
f_{1}(x) \\
f_{2}(x) \\
f_{3}(x)
\end{array}\right\}
$$

The number of objective function must be minimum two functions.

$$
\begin{gathered}
n_{o b} \geq 2 \\
x=\left\{x_{1} x_{2} \ldots x_{n}\right\}^{T} \leq 0
\end{gathered}
$$

subjected to the constraints:

$$
g_{x}=\left\{g_{1}(x) g_{2}(x) \ldots g_{n c}(x)\right\}^{T} \leq 0
$$

Where the scalar functions $\mathrm{f}(\mathrm{x})$ and $\mathrm{g}(\mathrm{x})$ are termed the multi - objective and constraint function, respectively. The vector $\mathrm{x}$ denotes the variables. The symbol $\mathrm{n}$ denotes the number of variables, and $\mathrm{nc}$ is the number of constrains.

Simulation results on a number of difficult test problems showed that the proposed Multi-objective Genetic Algorithm (MOGA), is able to find for most problems a much better spread of solutions and better convergence near the true Pareto-optimal front. However, we will modify the definition of dominance in order to solve constrained multi-objective problems efficiently.

The simulation results of the constrained MOGA on a number of test problems, including a triple - objective function, a triple - constraint non - linear problem, are compared with another constrained multi - objective optimizer and a much better performance of MOGA is observed.

The obtained results are show in figure 5 for cutting power and metal removal rate (MMR).

In many cases of real problems, multi - objective optimization problems involve multiple and conflicting objectives. Hence, the optimizing of machining variables with respect to a single objective function often results in unacceptable results with respect to the other objectives functions.

Described as a combined optimized scheduling model of automated manufacturing environments. Some models of automated facilities typically include tooling constraints that reflect the possibility of a machine using different tools in order to perform successive operations, within the limits imposed by the size of the tool's magazine $[8,9]$

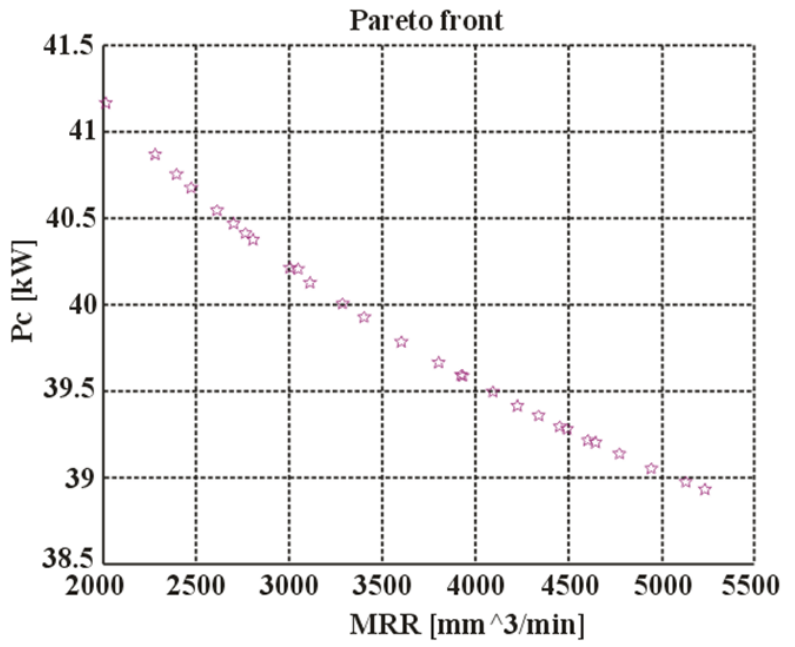

Figure 5. Obtained results for cutting power Pc and Metal removal rate MRR using Pareto Front

The authors presented the analyzing for tool path generation, tool selection and optimization of machining parameters by milling operation. Tool path is get to optimize the machining parameters and in same time to reduce the time. Also, an optimization model was developed as a nonlinear programming problem and solved using extended LINGO nonlinear software [10].

A reasonable solution to a multi - objective problem is to investigate a set of solutions, each of which satisfies the objectives at an acceptable level without being dominated by any other solution [12]. The first multi-objective GAs, called vector evaluated GAs.

The authors described tool sequence selection as an important activity in process-planning for milling and it has great bearing on the cost of machining. A Genetic Algorithm (GA) formulation is used to find the optimal tool sequence. Two types of selection mechanisms namely "Elitist selection" and "Roulette method" are tested [7], [13].

The main advantage of the proposed method is its ability to perform multi-object optimisation, minimum machining time and minimum production cost, whilst considering the technological and material constraints.

Afterwards several multi - objective evolutionary algorithms were developed including Multi - objective Genetic Algorithms (MOGAs). In order to implement optimization of the cutting force for turning process, three parameters are selected as the optimization variables such as: feed rate (f), depth of cutting (a) and cutting speed (v).

The optimum of the tool path length and cutting force is described, as follows:

$\min f(x)=\left[\right.$ tool pathlength - TPL, Cutting Force $\left.-F_{c}\right]$

subject to the constraints of the machining parameter: 


$$
\begin{aligned}
& X_{1 \min } \leq X \leq X_{1 \max } \\
& X_{2 \min } \leq X \leq X_{2 \max } \\
& X_{3 \min } \leq X \leq X_{3 \max }
\end{aligned}
$$

The goal functions needed for optimizing within the environment of a Multi-objective Genetic Algorithm and to find the best solution is described as follows.

$$
\begin{gathered}
T P L \leq T P L_{\max } \\
F_{c}\left(X_{1}, X_{2}, X_{3}\right) \leq F_{c \max }
\end{gathered}
$$

Clearly, the above optimisation process is a nonlinear programming problem. The optimisation procedure is realised in Multi - Objective Genetic Algorithms through Matlab environment.

The optimal values of the tool path length for the turning operation are determined by employing a Multi-Objective Genetic Algorithm, as shown in Table 3 for five independent runs. It can be concluded that the five independent run found similar results.

Table 3. Optimal results achieved from multi objective genetic algorithm results for five independent GA - runs

\begin{tabular}{|c|c|c|c|c|c|c|}
\hline \multirow{2}{*}{$\begin{array}{c}\text { Machining } \\
\text { parameters }\end{array}$} & \multirow{2}{*}{$\begin{array}{l}\text { Initial } \\
\text { values }\end{array}$} & \multicolumn{5}{|c|}{ Optimal values } \\
\cline { 3 - 7 } & GA 1 & GA 2 & GA 3 & GA 4 & GA 5 \\
\hline $\mathrm{a}[\mathrm{mm}]$ & 0.2 & 0.102 & 0.101 & 0.105 & 0.109 & 0.101 \\
\hline $\mathrm{f}[\mathrm{mm}]$ & 0.4 & 0.201 & 0.212 & 0.206 & 0.205 & 0.205 \\
\hline $\mathrm{V}[\mathrm{m} / \mathrm{min}]$ & 2.8 & 2.320 & 2.309 & 2.313 & 2.340 & 2.358 \\
\hline $\begin{array}{c}\text { Number of } \\
\text { generations }\end{array}$ & - & 193 & 116 & 261 & 267 & 112 \\
\hline
\end{tabular}

\section{Conclusions}

In this paper is proposed the MOGA to predict the cutting force significantly for tool path length and optimized the main machining parameters with five runs. The result with using of Multi-objective Genetic Algorithm (MOGA) enabled to analyse two or more function in same time as in our case cutting force, material removal rate MMR and tool path length. Also, the value of machining parameters are investigated for five independent runs as in table 1, and each runs in environments of Multi-objective Genetic Algorithm are different based on initial values of main machining parameters for case by turning operations.

The measurement of cutting force are compared and analyzed with Genetic Algorithm. The Multi - objective Genetic Algorithm in our case used to compare the results of experimental and theoretical measurement of cutting force $\mathrm{Fc}$, by turning operation. At same time is present the average of prediction error. The average of prediction error is take for $5 \%$ to investigate the cutting force which means that the experimental part was carried out under the conditions.
Obtained results for cutting power Pc and Metal removal rate MRR using Pareto Front with help of Multi-Objective Genetic Algorithm, is showed in figure 5.

Therefore, this study showed that AI/MOGA was a good alternative for other conventional modelling techniques in prediction of tool path length, main machining parameters and cutting forces - material removar rate.

\section{REFERENCES}

[1] A. Gjelaj, J. Balic, M. Ficko, Intelligent optimal tool selections for CNC programming of machine tools. Transactions of FAMENA, ISSN 1333-1124, vol. 37, no. 3, pp. 31-40, 2013.

[2] W. Navidi, Statistics for Engineers and Scientists, (1st edition, 2006), New York, America: The McGraw-Hill Companies.

[3] Konak A., David C., \& Alice S, Multi-objective optimization using genetic algorithms". A tutorial, Reliability Engineering and System Safety 91. pp: 992-1007 Published by Elsevier, 2006.

[4] S.J., Hinduja S., \& Barrow G., Automatic tool selection for rough turning operations". International Journal of Machine Tools and Manufacture Volume 29, Issue 4, pp. 535-553, 1989.

[5] J. Balic, M. Ficko, A. Salihu, A. Gjelaj, Optimization of cutting tool path generation using genetic algorithm". Annals of DAAAM proceedings of the 22nd International DAAAM symposium "Intelligent manufacturing \& Automation: "Power of knowledge and creativity", 23-26th November 2011, Vienna, Austria, (Annals of DAAAM \& Proceedings, ISSN 1726-9679). pp. 569-570.

[6] Zaryab A., Keyvan R., \& Roshan M. D’Souza, Applications of genetic algorithms in process planning: tool sequence selection for 2.5-axis pocket machining". Journal of Intelligent Manufacturing. Vol. 21. pp: 461-470, 2010.

[7] Hrelja M., Klancnik S., Balic J., \& Brezocnik M., Modelling of a turning process using the gravitational search algorithm" International Journal of Simulation modelling, ISSN 1726-4529. vol. 13, no1, pp. 30-41, 2014.

[8] Ariffanan M., Basri M., Danapalasingam KA., \& Husain AR., "Design and Optimization of Backstepping Controller for An Underactuated Autonomous Quadrotor Unmanned Aerial Vehicle". Transactions of FAMENA, Vol.38 No.3, pp 27-44, 2014.

[9] Yves Crama, Combinatorial optimization models for production scheduling in automated manufacturing systems. European Journal of Operational Research 99. pp. 136-153, 1997.

[10] Mwinuka T., \& Mgwatu M., Tool selection for rough and finish CNC milling operations based on tool-path generation and machining optimization, Advances in Production Engineering \& Management, ISSN 1854 - 6250.vol. 10 n.1 pp 18-26, 2015. 
[11] A. Gjelaj, Automated and Intelligent Programming of CNC machine tools, Dr.sc. Doctoral thesis, Dept. Mechanical Eng., University of Maribor, 2014.

[12] Schaffer J. D., Multiple objective optimization with vector evaluated genetic algorithms. Proceedings of the first International Conference on Genetic Algorithms. pp. 93$100,1985$.

[13] Ficko M., Balič J., Pahole, I., Šenveter J., Brezovnik S \& Klančnik S, Expectations of automatic programming of $\mathrm{CNC}$ machine tools. Advances in production engineering \& management, ISSN 1854-6250, vol. 5, no. 3, pp. 193-199, 2010 .

[14] Fuat Kara, Kubilay Aslantas, Adem Çiçek, Prediction of cutting temperature in orthogonal machining of AISI316L using artificial neural network. Applied Soft Computing 38 (2016) 64-74.

[15] Fuat Kara, Kubilay Aslantas, Adem Çiçek, ANN and multiple regression method-based modelling of cutting forces in orthogonal machining of AISI $316 \mathrm{~L}$ stainless steel. Neural Computing and Applications, 26(1) (2015) 237-250. 